$\mathrm{DE}$

M E D I C I N A

T R O P I C A L

$\mathrm{DE}$

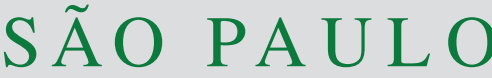

JOURNAL OF THE SÃO PAULO INSTITUTE OF TROPICAL MEDICINE

${ }^{1}$ University of California-Berkeley, School of Public Health, Division of Infectious Diseases and Immunity, Berkeley,

California, USA

2Universidade de São Paulo, Faculdade de Medicina, Departamento de Doenças Infecciosas e Parasitárias, São Paulo, São Paulo, Brazil

${ }^{3}$ Universidade de São Paulo, Faculdade de Medicina, Hospital das Clínicas, Laboratório de Virologia (LIM 52), São Paulo, São Paulo, Brazil

${ }^{4}$ Universidade de São Paulo, Instituto de Medicina Tropical de São Paulo, São Paulo, São Paulo, Brazil

${ }^{5}$ Universitat Politècnica de València, Instituto de Tecnología Química, Consejo Superior de Investigaciones Científicas, Valencia, Spain

Correspondence to: Miguel A. GonzálezCardenete

Universitat Politècnica de València, Instituto de Tecnología Química, Consejo Superior de Investigaciones Científicas, Avda. de los Naranjos, s/n, 46022, Valencia, Spain

Tel: +34 963877810 ,

Fax: +34 963879444

E-mail: migoncar@itq.upv.es

Received: 18 September 2020

Accepted: 17 November 2020

\section{Anti-Zika virus activity of several abietane-type ferruginol analogues}

Francielle T. G. Sousa ${ }^{1,2}$, Cristina Nunes ${ }^{2}$, Camila Malta Romano ${ }^{2,3,4}$, Ester Cerdeira Sabino $^{2,4}$, Miguel Angel González-Cardenete 5

\section{ABSTRACT}

Abietane diterpenoids are naturally occurring plant metabolites with a broad spectrum of biological effects including antibacterial, antileishmanial, antitumor, antioxidant, as well as antiinflammatory activities. Recently, we found that some analogues of natural ferruginol (2) actively inhibited dengue virus 2 (DENV-2) replication. Due to the similarity with DENV, we envisaged that abietane diterpenoids would also be active against Zika virus (ZIKV). Six selected semi-synthetic abietane derivatives of (+)-dehydroabietylamine (3) were tested. Cytotoxicity was determined by MTT assay in Vero cells. In vitro anti-ZIKV (clinical isolate, IMT17) activity was evaluated by plaque assay. Interestingly, these molecules showed potential as anti-ZIKV agents, with $\mathrm{EC}_{50}$ values ranging from 0.67 to $18.57 \mu \mathrm{M}$, and cytotoxicity $\left(\mathrm{CC}_{50}\right.$ values) from 2.56 to $35.09 \mu \mathrm{M}$. The 18-Oxoferruginol (8) $\left(\mathrm{EC}_{50}=2.60 \mu \mathrm{M}\right.$, $\mathrm{SI}=13.51)$ and 12-nitro-N-benzoyldehydroabietylamine (9) $\left(\mathrm{EC}_{50}=0.67 \mu \mathrm{M}, \mathrm{SI}=3.82\right)$ were the most active compounds, followed by 12-hydroxy-N-tosyldehydroabietylamine (7) $\left(\mathrm{EC}_{50}=3.58 \mu \mathrm{M}, \mathrm{SI}=3.20\right)$ and 12-hydroxy-N,N-phthaloyldehydroabietylamine (5) $\left(\mathrm{EC}_{50}=7.76 \mu \mathrm{M}, \mathrm{SI}=1.23\right)$. To the best of our knowledge, this is the first report on anti-Zika virus properties of abietanes.

KEYWORDS: Zika. Abietane. Diterpenoid. Semi-synthesis. Anti-ZIKV activity.

Zika virus (ZIKV) is an arbovirus of the Flaviviridae family, phylogenetically close to dengue virus and yellow fever. Zika virus is mainly transmitted by Aedes mosquitoes and usually causes a mild dengue-like illness that may include fever, cutaneous rash, malaise, headache, muscle and joint pain, and/or swollen lymph nodes. Neurological complications include Guillain-Barré syndrome and congenital malformations leading to microcephaly ${ }^{1}$. Although Zika virus outbreaks have declined after 2017, autochthonous transmission of ZIKV still occurs globally across at least 87 countries and territories, with the potential for re-emergence ${ }^{2}$. Since specific antiviral drugs or vaccines are not available, there is urgency in identifying antiviral agents, particularly new molecular scaffolds with potential novel mechanisms of actions.

Natural products have played a dominant role in the drug discovery efforts for the treatment of human diseases ${ }^{3}$. In fact, in 2015, small molecules accounted for 45 drugs as antivirals other than synthetic molecules or $70 \%$ overall based on natural products, indicating the potential of identifying new therapeutic candidates from natural sources ${ }^{3}$. The abietane diterpenoids are widely produced by conifers and plants belonging to the families Araucariaceae, Cupressaceae, Pinaceae, Podocarpaceae, and angiosperm species ${ }^{4}$. These natural products have a wide range of biological activities ${ }^{5}$. For example, dehydroabietic acid (1, DHA) (Figure 1), 


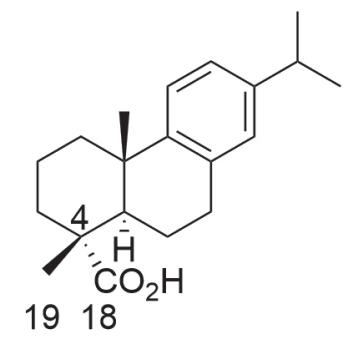

1, dehydroabietic acid<smiles>CC(C)c1cc2c(cc1O)[C@]1(C)CCC[C@H](C)[C@H]1CC2</smiles>

2, ferruginol

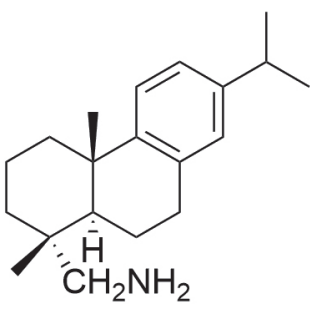

3, dehydroabietylamine

Figure 1 - Some typical bioactive abietane-type diterpenoids.

displays not only antiulcer and antimicrobial properties, but also antitumor effects. Ferruginol (2) (Figure 1) was first isolated in 1939 and has been extensively studied because of intriguing chemical framework and promising biological properties $^{6}$. Ferruginol (2) occurs in plants belonging to the Podocarpaceae, Cupressaceae, Lamiaceae and Verbenaceae families among others. This diterpene exhibited important bioactivities, such as antifungal and antimicrobial, miticidal, cardioactive, antioxidative, antileishmanial and nematicidal, antiulcer, and anti-SARS properties ${ }^{5}$. In addition, there are several reports on antimalarial activity of ferruginol $(2)^{7}$. Recently, it has been reported that several antimalarials are endowed with anti-DENV and anti-ZIKV activities ${ }^{8}$. We have also found that some analogues derived from (+)-dehydroabietylamine (3) (Figure 1) of the naturally occurring abietane ferruginol (2) (Figure 1) were active against DENV-2 ${ }^{9}$. The 12-hydroxyabieta-8,11,13-triene skeleton, which is characteristic of the diterpenoid ferruginol (2), is therefore an interesting molecular scaffold for the development of novel antivirals against flaviviruses.

To explore the potential of some selected analogues of ferruginol (2) as antiviral candidates, and in continuation of our research programs to discover bioactive terpenoids, herein we report the evaluation of previously synthesized semisynthetic derivatives $\mathbf{4 - 9}^{9-11}$ from the commercially available (+)-dehydroabietylamine (3) (Figure 1) against a Brazilian strain of ZIKV.

The compounds were obtained in enantiomerically pure form from commercially available (+)-dehydroabietylamine (3) (Figure1) according to our previously reported synthetic procedures ${ }^{9-11}$. The generated analogues are named as follows: 12-hydroxy-dehydroabietylamine (18-aminoferruginol, 4), 12-hydroxy-N,N-phthaloyldehydroabietylamine (5), 12-acetoxy-N,N-(tetrachlorophthaloyl)dehydroabietylamine (6), 12-hydroxy-Ntosyldehydroabietylamine (7), 18-oxoferruginol (8) and 12-nitro-N-benzoyldehydroabietylamine (9). Stock solutions of the tested compounds were prepared in dimethyl sulfoxide (DMSO) and maintained at $-20{ }^{\circ} \mathrm{C}$ until use.
The cytotoxicity of the ferruginol analogues 4-9 (Figure 2) was assessed on Vero cells (African green monkey kidney) by the MTT (3-(4,5-dimethylthiazol2-yl)-2,5-diphenyltetrazolium bromide) assay ${ }^{12}$. Vero cells suspensions $\left(2.7 \times 10^{5}\right.$ cells $\left./ \mathrm{mL}\right)$ prepared in MEM (Minimal Essential Medium, Vitrocell) with 5\% Fetal Bovine Serum (FBS, Gibco, Sao Paulo, Brazil) were distributed in 96-well plates (100 $\mu \mathrm{L} /$ well) and incubated at $37{ }^{\circ} \mathrm{C}\left(5 \% \mathrm{CO}_{2}\right)$ for $24 \mathrm{~h}$. Then, the culture medium was replaced by $200 \mu \mathrm{L}$ of two-fold serial dilutions of the compounds or DMSO. Cellular controls were treated with the culture medium only. After treatments, plates were further incubated at $37{ }^{\circ} \mathrm{C}$ for 4 days. Subsequently, $15 \mu \mathrm{L}$ of the MTT solution $(5 \mathrm{mg} / \mathrm{mL})$ were added per well, and the plates were incubated again for $4 \mathrm{~h}$. The MTT solution was removed and $100 \mu \mathrm{L}$ of DMSO were added to dissolve formazan crystals. Finally, the plates were shaken and absorbance was read at $540 \mathrm{~nm}$. The viability percentage data for each tested concentration of the compounds were entered in the GraphPad Prism software (version 5.01, San Diego, California, USA) to calculate the $\mathrm{CC}_{50}$ values, the concentration of compound that causes a 50\% reduction in cell viability, through regression analysis.

Zika virus (clinical isolate, IMT17) stock was produced and titrated in Vero cells. The viral titer, $4.67 \times 10^{6}$ plaque forming units per milliliter $(\mathrm{PFU} / \mathrm{mL})$, was determined by plaque assay ${ }^{13}$. The potential anti-ZIKV activity was evaluated by viral plaque reduction assay. Briefly, Vero cells $\left(1.5 \times 10^{5}\right.$ cells/well $)$ were grown in 24-well plates for $24 \mathrm{~h}$. After that, cells were infected with $100 \mathrm{PFU} /$ well and incubated for $1 \mathrm{~h}$ in a humidified $37^{\circ} \mathrm{C}$ incubator with $5 \% \mathrm{CO}_{2}$. Cells were then washed with PBS (pH 7.0) and treated with different concentrations of each compound [diluted in $2 \mathrm{X} \mathrm{MEM}$ with 2\% FBS and 50\% high viscosity carboxymethyl cellulose (CMC, Sigma)]. Ribavirin was used as the positive control. Medium only and DMSO were used as untreated and solvent controls, respectively. After 4 days of incubation at $37{ }^{\circ} \mathrm{C}, 5 \% \mathrm{CO}_{2}$, supernatants were removed, and cells were fixed and stained with $50 \%$ crystal violet in $50 \%$ ethanol. Plaque numbers 
<smiles>CC(C)c1cc2c(cc1O)[C@]1(C)CCC[C@](C)(CN)[C@]1(C)CC2</smiles>

4, 18-aminoferruginol<smiles>[CH]CCC[C@]1(C)c2cc(O)c(C(C)C)cc2CC[C@@]1(C)CNS(=O)(=O)c1ccc(C)cc1</smiles>

7, 12-hydroxy-N-tosyl-dehydroabietylamine<smiles>CC(C)c1cc2c(cc1O)[C@]1(C)CCCC(C)(C)[C@@]1(C)CC2</smiles><smiles>CC(=O)Oc1cc2c(cc1C(C)C)CC[C@@]1(C)C(C)(C)CCC[C@]1(C)C2=O</smiles>

5, 12-hydroxy-N,N-phthaloyldehydroabietylamine 6, 12-acetoxy-N,N-(tetrachloro)phthaloyldehydroabietylamine<smiles>CC(C)c1cc2c(cc1[N+](=O)[O-])[C@]1(C)CCC[C@](C)(CNC(=O)c3ccccc3)[C@@]1(C)CC2</smiles>

9, 12-nitro-N-benzoyl-dehydroabietylamine

Figure 2 - Abietane analogues selected to test anti-Zika virus activity.

were used to calculate the inhibition percentage values in order to determine the $\mathrm{EC}_{50}$, the concentration of the compound that inhibits viral replication by $50 \%$, through non-linear regression analysis using the GraphPad Prism. Compounds efficacy was determined by the selectivity index $\left(\mathrm{SI}=\mathrm{CC}_{50} / \mathrm{EC}_{50}\right)$, the ratio between cytotoxicity and antiviral activity.

Cytotoxicity and antiviral assay results of the compounds 4-9 are shown in Table 1. The 12-Nitro-Nbenzoyldehydroabietylamine (9) $\left(\mathrm{EC}_{50}=0.67 \mu \mathrm{M}, \mathrm{SI}=3.82\right.$ and $\left.\mathrm{EC}_{90}=0.89 \pm 0.004 \mu \mathrm{M}\right)$ and 18-oxoferruginol (8) $\left(\mathrm{EC}_{50}=2.60 \mu \mathrm{M}, \mathrm{SI}=13.51\right.$ and $\left.\mathrm{EC}_{90}=20.79 \pm 3.75 \mu \mathrm{M}\right)$ were the most active antiviral compounds, followed by 12-hydroxy-N-tosyldehydroabietylamine (7) $\left(\mathrm{EC}_{50}=3.58 \mu \mathrm{M}, \mathrm{SI}=3.20\right)$ and 12 -hydroxy-N,Nphthaloyldehydroabietylamine $(5)\left(\mathrm{EC}_{50}=7.76 \mu \mathrm{M}\right.$, $\mathrm{SI}=1.23$ ).

Inhibitory values against Zika virus ranged from 0.67 to $18.57 \mu \mathrm{M}$, with cytotoxicity properties varying from 2.56 to $35.09 \mu \mathrm{M}$. All compounds presented $\mathrm{EC}_{50}$ values lower than the reference ribavirin $\left(\mathrm{EC}_{50}=98.53 \mu \mathrm{M}\right)$, although ribavirin displayed a higher SI value (26.25). The resulting experimental data indicate that nitro derivative
Table 1 - Cytotoxicity and anti-ZIKV activity of compounds 4-9.

\begin{tabular}{lccc}
\hline \multirow{2}{*}{ Compound } & Cytotoxicity & $\begin{array}{c}\text { Anti-ZIKV } \\
\text { activity }\end{array}$ & \multirow{2}{*}{$\mathrm{SI}^{\mathrm{c}}$} \\
\cline { 2 - 3 } & $\mathrm{CC}_{50}{ }^{\mathrm{a}}(\mu \mathrm{M})$ & $\mathrm{EC}_{50}{ }^{\mathrm{b}}(\mu \mathrm{M})$ & \\
\hline $\mathbf{4}$ & $28.33 \pm 3.44$ & $18.57 \pm 1.00$ & 1.53 \\
$\mathbf{5}$ & $9.51 \pm 0.76$ & $7.76 \pm 0.74$ & 1.23 \\
$\mathbf{6}$ & $34.04 \pm 7.35$ & $11.52 \pm 0.08$ & 2.95 \\
$\mathbf{7}$ & $11.46 \pm 1.95$ & $3.58 \pm 0.59$ & 3.20 \\
$\mathbf{8}$ & $35.09 \pm 5.20$ & $2.60 \pm 0.07$ & 13.51 \\
$\mathbf{9}$ & $2.56 \pm 0.45$ & $0.67 \pm 0.07$ & 3.82 \\
Ribavirin & $2,586.50 \pm 318.91$ & $98.53 \pm 6.46$ & 26.25 \\
\hline
\end{tabular}

Values represent the means \pm SD of at least two independent experiments; ${ }^{\mathrm{a}} \mathrm{CC}_{50}=50 \%$ cytotoxic concentration on Vero cells; ${ }^{b} \mathrm{EC}_{50}(\mu \mathrm{M})=50 \%$ effective concentration against ZIKV replication by plaque assay; 'Selectivity index $(\mathrm{SI})$ : ratio between cytotoxicity and antiviral activity $\left(\mathrm{CC}_{50} / \mathrm{EC}_{50}\right)$.

(9) displayed potent antiviral activity but possess a certain cytotoxicity. Compound 18-oxoferruginol (8) presented the most promising results with a higher selectivity index $(\mathrm{SI}=13.51)$. According to Chattopadhyay et al. ${ }^{14}$ a SI of 10 or greater is indicative of a promising antiviral activity. 
Therefore, it has been demonstrated that abietane-derived compounds represent a novel scaffold for the development of anti-Zika virus agents. To the best of our knowledge, this is the first report on anti-ZIKV activity of abietane-type diterpenoids. These encouraging findings warrant synthetic endeavors to get structure-activity relationships, as well as further mechanism of action and target identification studies.

\section{AUTHORS' CONTRIBUTIONS}

FTGS: conceptualization, data collection and analysis, investigation, methodology, validation, writing - original draft, review and editing; $\mathrm{CN}$ : data collection and analysis, investigation, methodology, writing - original draft; CMR: conceptualization, resources, supervision, validation; ECS: project administration, resources, and supervision; MAGC: conceptualization, formal analysis, funding acquisition, investigation, methodology, project administration, resources, supervision, visualization, writing - original draft, writing - review and editing. All authors revised the final version of the manuscript.

\section{CONFLICT OF INTERESTS}

The authors have no conflict of interests to disclose.

\section{FUNDING}

Financial support from the Universitat Politècnica de Valencia, under a cooperation "ADSIDEO" research grant (AD1902), is gratefully acknowledged. We are also gratefully to the financial support of the Sao Paulo Research Foundation (FAPESP), grants No 2013/01690-0, $N^{\circ}$ 2019/03859-9, and FAPESP Scholarship No 2013/017029 to FTGS.

\section{REFERENCES}

1. Noorbakhsh F, Abdolmohammadi K, Fatahi Y, Dalili H, Rasoolinejad M, Rezaei F, et al. Zika virus infection, basic and clinical aspects: a review article. Iran J Public Health, 2019;48:20-31
2. World Health Organization. Countries and territories with current or previous Zika virus transmission, by WHO regional office. [cited 2020 Nov 17]. Available from: https://www.who.int/ emergencies/diseases/zika/countries-with-zika-and-vectorstable.pdf

3. Newman DJ, Cragg GM. Natural products as sources of new drugs over the nearly four decades from $01 / 1981$ to $09 / 2019$. J Nat Prod. 2020;83:770-803.

4. Hanson JR, Nichols T, Mukhrish Y, Bagley MC. Diterpenoids of terrestrial origin. Nat Prod Rep. 2019;36:1499-512.

5. González MA. Aromatic abietane diterpenoids: their biological activity and synthesis. Nat Prod Rep. 2015;32:684-704.

6. Brandt CW, Neubauer LG. Miro resin. Part I. Ferruginol. J Chem Soc. 1939;1031-7.

7. González MA, Clark J, Connelly M, Rivas F. Antimalarial activity of abietane ferruginol analogues possessing a phthalimide group. Bioorg Med Chem Lett. 2014;24:5234-7.

8. Balasubramanian A, Teramoto T, Kulkarni AA, Bhattacharjee AK, Padmanabhan R. Antiviral activities of selected antimalarials against dengue virus type 2 and Zika virus. Antivir Res. 2017;137:141-50.

9. Roa-Linares VC, Brand YM, Agudelo-Gomez LS, TangarifeCastaño V, Betancur-Galvis LA, Gallego-Gomez JC, et al. Anti-herpetic and anti-dengue activity of abietane ferruginol analogues synthesized from (+)-dehydroabietylamine. Eur J Med Chem. 2016;108:79-88.

10. González MA, Pérez-Guaita D. Short syntheses of (+)-ferruginol from (+)-dehydroabietylamine. Tetrahedron. 2012;68:9612-5.

11. Dea-Ayuela MA, Bilbao-Ramos P, Bolás-Fernández F, GonzálezCardenete MA. Synthesis and antileishmanial activity of C7and $\mathrm{C} 12$-functionalized dehydroabietylamine derivatives. Eur J Med Chem. 2016;121:445-50.

12. Cory AH, Owen TC, Barltrop JA, Cory JG. Use of an aqueous soluble tetrazolium/formazan assay for cell growth assays in culture. Cancer Commun. 1991;3:207-12.

13. Burleson FG, Chambers TM, Wiedbrauk DL. Virology: a laboratory manual. San Diego: Academic Press; 1992.

14. Chattopadhyay D, Sarkar MC, Chatterjee T, Sharma Dey R, Bag P, Chakraborti S, et al. Recent advancements for the evaluation of anti-viral activities of natural products. $\mathrm{N}$ Biotechnol. 2009;25:347-68. 